KAWISTARA

VOLUME 4

No. 2, 17 Agustus 2014

Halaman 111-224

\title{
ANTARA RASA DAN ESTETIKA KOMODIFIKASI NILAI KONSUMSI PADA PANGAN SEBAGAI WUJUD EKSISTENSI
}

\author{
Michael HB Raditya \\ Program Studi Pengkajian Seni Pertunjukan dan Seni Rupa \\ Sekolah Pascasarjana Universitas Gadjah Mada \\ Email: michael.raditya@gmail.com
}

\begin{abstract}
Nowadays, massively development of food consumption makes many changes, including the human biological element, the eating activity. In Earlier, taste of food is a priority in exchange value, but everythings be changed because the new concept about presentation and appearance of food itself. The presentation of food becomes important and creates more value for the food. Appearance is the main stimulant for the food to deciding the taste from the food itself. In deep researched, implicity, the condition emphasis that happened about commodifiation of exchange value in food perspective. Discussing about value in food, is a form of commodification and has correlation with society existence. To solve the problem, ethnofraphy and art perspective method is a source to analyzing data, with interviews and literature studies as a source of data, to interpret and respond the phenomena. The results of researched had founded, art is the new element in value exchange of food. Food and art created an aesthetic and enchant point, and giving a higher price. The high consumerism pattern makes aesthetic food as a symbol of class existence. The high value on aesthetic food becomes a reference for society to show who they are. The food created, not only because the food itself, but also the contextual makes the food more essential.
\end{abstract}

Keywords: Food, Aesthetics, Commodification, Existence, Enchantment.

\begin{abstract}
ABSTRAK
Dewasa ini, perkembangan konsumsi pangan yang masif membentuk banyak perubahan, termasuk pada unsur biologis manusia, yaitu aktifitas makan.Makanan yang pada awalnya mengedepankan rasa sebagai prioritas nilai pertukaran, menjadi berubah dengan adanya konsep penyajian dan penampilan pada makanan.Penyajian pada makanan menjadi penting dan menjadi nilai tersendiri bagi makanan tersebut. Penampilan menjadi stimulan utama bagi makanan untuk menentukan rasa dari makanan tersebut.Ditilik lebih lanjut, secara implisit menegaskan bahwa terjadi komodifikasi pertukaran nilai pada makanan. Mengupas nilai pada makanan sebagai wujud komodifikasi yang berkorelasi dengan eksistensi masyarakat. Dalam menjawab permasalahan, etnografi dan metode penelitian seni menjadi sumber analisa data, dengan wawancara dan studi literatur sebagai kekayaan data, untuk menafsirkan dan menjawab fenomena yang ada.Hasil penelitian yang ditemukan adalah seni merupakan unsur baru dalam pertukaran nilai pada makanan.Makanan dan seni membentuk makanan mempunyai estetik dan pesona tersendiri, sehingga memberikan harga jual yang lebih tinggi.Pola konsumerisme masyarakat yang tinggi menjadikan makanan estetik sebagai lambang eksistensi kelas pada masyarakat.Tingginya nilai harga pada makanan estetik menjadi acuan masyarakat untuk menunjukan diri mereka. Makanan tidak terbentuk karena makanan itu sendiri, tetapi kontekstual pada makanan ikut membentuk makanan menjadi lebih esensial.
\end{abstract}

Kata Kunci: Makanan, Estetika, Komodifikasi, Eksistensi, Pesona. 


\section{PENGANTAR}

"I was born in 1951, when gardens and farming were commonplace. If you didn't have a garden, you didn't eat as well. A lot of people were still making what you would consider a living by farming. Some had cows. Some had chickens, some had pigs. Not everybody had all of those things. But it was a farming community, so you didn't need to-you could barter for whatever you needed.

Patricia Kliendienst - The Earth Knows My Name

Kliendienst dalam telaahnya menceritakan tentang aktivitas dalam mengkonsumsi pangan sebagai kebutuhan yang primer.Bila halnya masyarakat tidak mempunyai lahan, maka mereka tidak dapat mengkonsumsi pangan.Lahan dan pertanian menjadi sebuah kesatuan yang tidak dapat terpisahkan. Serupa dengan Kliendienst, Koentjaraningrat (1994:168) mengemukakan bahwa sejak lama petani jawa menanam hasil bumi dalam bidang-bidang tanah. Pelzer (1963:124) juga menambahkan bahwa 15 tahun yang lalu dilaporkan bahwa setiap petani Jawa rata-rata memiliki setengah hektar tanah yang terbagi atas tegalan dan sawah. Secara eksplisit dapat dilihat bahwa setiap masyarakat mempunyai lahan sebagai modal dalam bertani. Telaah lebih lanjut menjelaskan bahwa pertanian merupakan lumbung kehidupan masyarakat. Masyarakat dengan basis agrikultur melakukan barter dalam memenuhi konsumsi pangan mereka dalam melengkapi kebutuhannya. Terjadi pertukaran hasil pangan yang didasarkan atas kebutuhan. Hal ini secara implisit menjelaskan bahwa masyarakat bersifat subsisten dalam memenuhi kebutuhan pangannya.

Menilik dalam proses pertukaran yang lebih modern, mata uang dianggap sebagai formulasi yang tepat dalam melakukan pertukaran. Pada awalnya pertukaran dilakukan secara langsung antara barang satu dengan barang yang lain, dengan kondisional saling membutuhkan. Menjadi terwakilkan dengan sebuah benda bernama "uang" sebagai alat tukar, dengan kondisional tidak bersyaratkan pertukaran kebutuhan seperti barter. Pertukaran tersebut memperlihatkan perubahan sistem transaksional dalam keberlangsungannya. Tidak adanya lagi penawaran, pertukaran, dan patronase, tetapi lebih pada sistem transaksi antara individu dengan individu lain. Konsep pertukaran ini menjadi telaah yang menarik mengingat majemuknya perkembangan yang terjadi pada lingkup masyarakat rural dan urban kini. Konsep pertukaran nilai menjadi hal yang menarik dalam pembahasannya. Appadurai (1986:4) mengatakan bahwa in economic value, is generated by this sort of exchange of sacrifices. Pernyataan Appadurai menekankan bahwa adanya pertukaran pengorbanan atas sebuah hal. Pertukaran tidak hanya dianggap sebagai sebuah aktivitas menukarkan, tetapi lebih pada pertukaran nilai dari hal yang ditukarkan.

Konsep pertukaran nilai menjadi landasan dasar dalam melihat fenomena budaya konsumsi pangan, yang dispesifikan pada nilai terhadap makanan. Dewasa ini, tidak dapat dipungkiri bahwasanya makanan tidak hanya tersedia sebagaimana mestinya. Makanan mengalami perubahan bentuk dan fungsi dalam nilai makanan itu sendiri. Terlebih ketika makanan menjadi komoditi utama dalam keberlangsungan hidup. Penyajian suatu jenis makanan akan menjadi pertimbangan lain selain rasa makanan. Bahkan terkadang penyajian atau penampilan menstimulasi para konsumen dalam merasakan makanan tersebut, dan sebaliknya. Makanan cantik, makanan artistik, makanan yang estetik, bahkan makanan yangdianggap“nyeni". Dapat dikatakan bahwa seni menjadi alasan utama dalam menilik perubahan yang terjadi dalam nilai makanan. Proses komodifikasi nilai makanan tersebut, yaitu makanan yang dibalut seni menjadi komoditas utama dalam produksi, bahkan menjadi tren tersendiri belakangan ini.

Asumsi yang dapat diproyeksi adalah terjadi perubahan terhadap nilai makanan, dari yang bersifat sederhana menjadi sesuatu yang kompleks. Kompleks dalam pemahaman lebih lanjut adalah nilai makanan tidak hanya sebagai makanan saja, tetapi 
adanya pembentukan kontekstual terkait. Pembentukan kontekstual sebenarnya sudah terbentuk sejak dahulu, makanan tidak hanya berdiri sendiri sesuai dengan fungsinya sebagai makanan, tetapi pembedaan kelas dengan dalih kebudayaan. Salobir (2011:13) mengemukakan bahwa:

In food production and consumption, there was no clear-cut colonial divide between two opposing sides. I have examined whether certain foods consumed by the colonizer were peculiar to each colony. This study argues that the colonial experience was a fluid enterprise and foods eaten bycolonizers in each colony made geographical leaps to other colonies, and, in the process, post-colonial societies adopted and adapted to 'colonial foods'. Anglo-Indians came from different occupational backgrounds, from the armed forces, administration and commerce, and different classes with different dietary habits. The colonized in India were from different castes and classes, again with different dietary practices, and these influenced the food practices of AngloIndians. Thus, the colonial cuisine was a hybrid cuisine with some elements of British foodways and components of foodways from the colonies.

Salobir memperlihatkan bahwa terjadi pembedaan jenis makanan antara makanan kolonial dan Anglo Indian. Telaah lebih lanjut bahkan berimplikasi lebih dalam bahwasanya kebiasaan makan, kelas, dan kasta menjadi pembeda jenis makanan.

Pada telaah lainnya, Appadurai (1981: 495) juga mengemukakan sebagai berikut:

Goes on to say that cuisine is both highly developed and highly differentiated. For instance, he states that food avoidances, for different persons in different contexts, are developed to a remarkably high degree and can signal caste or sect affiliation, life cycle stages, gender distinctions and aspirations towards higher status.

Appadurai mempertegas pembedaan dengan mencontohkan masyarakat Hindi di Asia Selatan, di mana bahwa makanan mempunyai aplikasi dalam pembangunan dan perbedaan. Satu individu mempunyai perbedaan konteks yang melekat, disesuaikan dengan tinggi pangkat dan tingginya kasta, panggung, siklus hidup, pembedaan gender, dan menjadi aspirasi lebih lanjut dalam menentukan tingginya status. Mulai dari pembedaan dan perbedaan jenis makanan itulah terbentuk bahwa makanan tidak hanya menjadi makanan, tetapi bagaimana makanan membentuk masyarakat sesuai dengan kebudayaan yang melekat. Setiap kasta atau pembedaan masyarakat, baik yang dibentuk secara politik kolonial atau politik keagamaan, membentuk klasifikasi yang kuat antara jenis makanan. Masyarakat dengan status yang lebih tinggi akan mengkonsumsi makanan yang-dikonstruksi lebih-“beradab”.

Konstruksi pembentukan makanan tidak terjadi serta-merta, beberapa alasan yang sudah diutarakan Salobir dan Appadurai mengisyarakatkan bahwa adanya kontekstual yang kuat, dan itu adalaha kultur. Senada dengan Kliendiest (2006:101) yang menyatakan bahwa I feel that the landscape of food, culture, and community are completely tied together, but in our society we've completely separated them. Artinya bahwa pelaku utama dalam pembedaan makanan adalah masyarakat, makanan, kebudayaan, dan komunitas bersama. Masyarakat yang membedakan serta memisahkan makanan yang satu dengan yang lain. Akan tetapi, terdapat poin yang tetap berdiri bahwasanya makanan terbentuk berdasarkan kebudayaan. Penerapan nilai makanan inilah yang kembali berangsur berubah sejalan dengan masifnya perkembangan. Beberapa pengalaman seperti efek kolonial efek dan efek agama membentuk adanya landasan pada makanan itu berbeda dan adanya nilai lebih untuk membedakan. Artikel inilah penulis akan mengupas nilai pada sebuah makanan sebagai wujud komodifikasi yang berkorelasi dengan eksistensi bagi masyarakatnya. Proses komodifikasi berimplikasi padaeksistensipara konsumen, dan secara eksplisit menjelaskan bahwa meningkatnya pola konsumerisme didasari oleh hal tersebut.

Menguak permasalahan yang ada, penelitian dilakukan dengan menggunakan metode penelitian etnografi dan metode penelitian seni dalam mengintepretasikan 
proses komodifikasi nilai pangan. Spreadley (2007:xxi) berpendapat bahwa etnografi merupakan metode yang menemukan dan menggambarkan organisasi pikiran dari manusia yang di dalamnya terdapat kebudayaan. Lebih mudahnya, pembacaan lebih mendalam atas permasalahan dapat dilakukan dengan metode ini. Teknik pengumpulan data kualitatif menjadi pilihan yang tepat dalam mengumpulkan data. Wawancara menjadi data primer dalam melihat kemajemukan masyarakat yang terhegemoni oleh masifnya pola konsumerisme, dan studi literature mengimbangi wawancara sebagai data utama. Pembacaan seni yang dikhususkan pada estetika dan artistik dianggap dapat menjawab secara eksplisit atas seni tersebut. Hasil temuan akan menjadi refleksi dalam melihat permasalahankomodifikasi nilai yang berhubungan dengan eksistensi-dengan sudut pandang seni, sebagai sebuah manifesto kebudayaan.

\section{PEMBAHASAN \\ Makanan dan Seni: Rasa atau Penampilan?}

Budaya membentuk nilai esensial pada sebuah makanan, tetapi ada kalanya nilai makanan terbentuk karena makanan itu sendiri. Pada dasarnya Parasecoli (2008:17) mengatakan bahwa makanan sebagai:

When they eat and drink, individuals find themselves at the juncture between biological necessity, the world of drives and instincts, the inputs from the outside world, and the tremendous landslide of sensations, feelings, and emotions resulting from uninterrupted brain activities.

Parasecoli lebih menganalogikan makanan sebagai kebutuhan biologik dan kebutuhan manusiawi. Makanan turut serta membentuk sensasi, perasaan, dan emosi sebagai hasil aktivitas kognitif. Kebutuhan yang selalu, dan dikaitkan dengan insting, memberikan pemahaman bahwa makanan dibutuhkan setiap hari. Terkait dengan hal tersebut, Mints (2008:21) mengartikan makanan sebagai: in society is a culturally inflected vehicle of symbolic meaning. So prosaic and everyday, and yet so vital, food is among the most powerful of all social indices of difference and identity.

Mints dalam pemahaman yang lebih mendalam memperlihatkan bahwa dalam masyarakat, aktivitas makan sebuah makanan mempunyai nilai simbolik tersendiri. Makanan di konsumsi setiap hari dan menjadi sesuatu yang prioritas. Makanan merupakan kekuasaan terkuat dalam menentukan perbedaan dan identitas.

Melanjutkan Mints, terkait dengan hal serupa Parasecoli (2008:2) juga menekankan bahwa makanan mempunyai artian yang lebih sebagai berikut:

Food is pervasive. The social, economic, and even political relevance cannot be ignored. Ingestion and incorporation constitute a fundamental component of our connection with reality and the world outside our body. Food influences our lives as a relevant marker of power, cultural capital, class, gender, ethnic, and religious identities.

Makanan merupakan sebuah perpaduan aktivitas dalam tataran sosial, ekonomi, bahkan relevansi politik. Makanan, aktivitas makan dan jenis makanan dipengaruhi oleh relevansi kehidupan terhadap kekuasaan, kebudayaan kapital, pembagian kelas, pembedaan gender, etnik, dan identitas agama. Dari telaah di atas, secara eksplisit dapat dilihat bahwasanya makanan terbentuk dengan kontekstual yang kuat. Terkait dengan hal tersebut, dewasa ini pembentukan makanan yang didasarkan pada konsep "nyeni" merupakan hasil pembentukan konseptual dari kontekstual yang ada.

Konteks seni menjadi esensial melihat masifnya perkembangan makanan nyeni. Kembali menilik seni itu sendiri Geertz (1976:1473) menyatakan sebagai berikut:

Art is notoriously hard to talk about. It seems, even when made of words in literary arts, all the more so when made of pigment, sound, stone, or whatever in the non-literary ones, to exist in a world of its own, beyond the reach of discourse. It not only is 
hard to talk about it; it seems unnecessary to do so. It speaks, as we say for itself: a poem must not mean but be; if you have to ask what jazz is you are never going to get to know.

Geertz mengisyarakatkan bahwa seni merupakan perkara yang sulit dimengerti jikalau hanya melihat dari permukaan. Seni membutuhkan sebuah tindakan lebih untuk mengenalnya. Secara implisit menyatakan bahwa mengenal seni dengan mendalami seni itu sendiri tanpa melakukan tindakan seni itu sendiri. Telaah lebih lanjut adalah adanya tindakan dan pengalaman verbal yang menubuh, sehingga pengalaman seni turut membentuk sesuatu yang lebih dari apa yang dilakukannya. Terdapat esensi yang lebih bila halnya mempunyai pengalaman atau penubuhan terhadap seni itu sendiri.

Senada dengan apa yang diungkapkan Geertz, Soedarso (2006:54) mengutip Veron dan Tolstoy menyatakan bahwa seni merupakan mengekspresikan keseluruhan emosi manusia, baik yang menyenangkan ataupun yang menyedihkan. Sedangkan di timur, Sudjojono berpendapat bahwa seni adalah jiwa yang nampak. Kutipan dari Soedarso menguatkan bahwa seni merupakan pembicaran emosi, jiwa, dan lebih kepada perasaan. Kedalaman inilah yang menjadi sebuah nilai bahwa seni merupakan tindakan yang semata-mata terjadi pada pengalaman verbal, tetapi nonverbal, sehingga tahapan lebih lanjut bila masakan dan seni digabungkan:

It is traditionally accepted that music is an art, that painting is an art, that theater is an art-no less than literature and, for more than a century now, the cinema. Why not cooking? Its essential function of providing nourishment has caused us to forget that, in the hands of a great cook, a meal is capable of touching us as a love song does, of giving us joy, occasionally even of moving us to anger.(This dan Gagnaire, 2008:9)

This dan Gagnaire mengemukakan kegelisahan tentang artian seni itu sendiri yang diaplikasikan terhadap sebuah aktivitas yang esensial, yaitu memasak. Mengapa memasak bukan bagian dari seni, ketika pengertian seni yang paling sederhana sudah memenuhi karakteristik untuk mengemukakan bahwa aktivitas memasak sebagai bagian dari seni. Ada hal yang terkait emosi, jiwa, dan perasaan yang terjadi dalam proses tersebut. Telaah lebih dalam mengimplisitkan bahwa memasak bagian dari seni dan hasil masakan merupakan produk seni, terlebih makanan yang disediakan dengan polesan gaya seni tertentu.

Telaah lebih mendalam dari kaitan masakan dan seni itu sendiri adalah pada rasa dan penampilan dari sebuah makanan. Bila halnya didasarkan pada rasa, Civitello (2008:XVI) menyatakan bahwa:

Taste is determined by culture, anatomy, and genetics. Almost everything we eat, and when, and where, is culturally determined, so taste is taught. Some people pay top dollar for escargot in fine restaurants while others stomp on the same snail when they find it in the garden. One person's haute cuisine is another person's pest. Taste is also anatomically determined. Scientists categorize people as "tasters" or "non-tasters." Which category you fall into depends on how many taste buds you have on your tongue - an inherited trait.

Ada beberapa hal yang menentukan sebuah rasa pada makanan, yaitu kebudayaan, anatomi, dan genetik. Kebiasaan yang menubuh pada individu dan kelompok menentukan dasar dari rasa itu sendiri. Rasa pada masakan juga membudaya ketika mentradisi dan diberlakukan secara turun menurun. Civitello juga mengungkapkan bahwa ada beberapa kelompok orang yang mengonsumsi makanan dengan harga yang mahal, dan sebaliknya. Bahkan terdapat kategori antara mereka yang lebih banyak dalam merasakan makanan (tester makanan).

Dewasa ini yang terjadi lebih bervariasi, tidak hanya rasa yang dapat membuat makanan menjadi begitu enak, tetapi penampilan dan penyajian dari makanan itu sendiri. Penulis menilik terjadi peningkatan pembuatan café dan resto ala borjuis di Yogyakarta, makanan yang disajikan didominasi oleh makanan ala barat yang membutuhkan penyajian yang lebih mewah. Faktanya bahwa gambar makanan tersebut menghiasi daftar menu makanan atau 
dinding dari café dan resto tersebut. Adapun yang dikemukakan oleh Monika sebagai konsumen:

Dengan melihat gambarnya, saya merasa tertarik, memesan dan menjatuhkan pilihan saya pada makanan ini. Penampilan dan penyajian yang menarik membuat saya percaya kalau makanan ini enak untuk dimakan dan dilihat (April,2014).

Pernyataan Monika dalam melihat makanan menjelaskan secara implisit bahwa makanan yang enak dapat dilihat dari penyajian dan penampilan yang cantik, atau estetik. Sedangkan rasa dari makanan seakan menjadi hal kedua yang dipikirkan. Hal tersebut tidak terjadi pada Monika saja, tetapi juga pada Amal:

Saya makan di café, walau harganya agak mahal tapi saya tidak mempermasalahkan karena tampilan makanan yang menarik, dan saya ga ragu walau yang saya pesan seperti jajanan pasar (April, 2014).

Pernyataan Amal diatas menjelaskan, walaupun jenis makanan memiliki kesamaan dengan makanan lain, tetapi dengan penampilan yang berbeda membuat nilai "enak" pada makanan lebih terasa. Adapun salah satu jenis makanan yang ditampilkan dengan penyajian dan penampilan yang menarik.

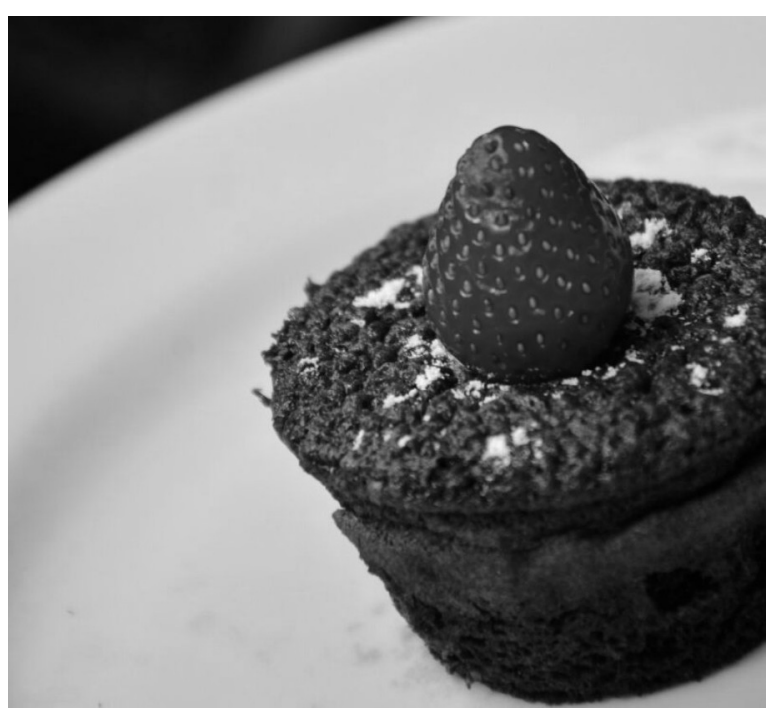

Gambar 1. Makanan Gaya Estetik Sumber: Foto Pribadi Milik Tyas, 2014
Darigambardiatas, tidakdapatdipungkiri, penampilan dari makanan tersebut menarik untuk dilihat, walaupun belum mengetahui rasa dari makanan tersebut. Implikasi yang muncul dari penampilan yang menarik adalah ketertarikan untuk mengkonsumsinya. Makanan dengan penampilan yang menarik makin diminati seiring menjamurnya tempat seperti café dan resto yang tersebar dengan masifnya. Dua informan tersebut merupakan hanya segelintir saja dalam arus kemajemukan jaman, di mana dalam nilai makanan, tidak hanya rasa, tetapi penampilan menjadi sebuah bahan pertimbangan untuk memilih makanan tersebut.

\section{Estetika dan Pesona pada Makanan}

Pada subbab sebelumnya, arah tulisan mengarahkan pada konsep makanan yang tidak hanya didasarkan pada rasa, tetapi pada penampilan. Penampilan dari makanan tidak hanya pada jenis makanan barat saja, tetapi juga pada masakan timur yang disajikan dengan cara dan penyajian barat. Seperti halnya, penyajian tempe dengan embelembel Steak, seperti halnya disebuah tempat makan, steak tempe menjadi makanan utama resto tersebut. Cara mengonsumsinyajuga menggunakan garpu dan pisau. Tidak hanya pada gaya, estetika penyajiannya pun menjadi bahan pertimbangan ketika makanan disediakan. Tidak hanya pada tempe, banyak jenis makanan lokal yang disulap menjadi makanan yang estetik. Adapun gambar yang memperlihatkan makanan ber-estetik walaupun dengan materi makanan lokal.

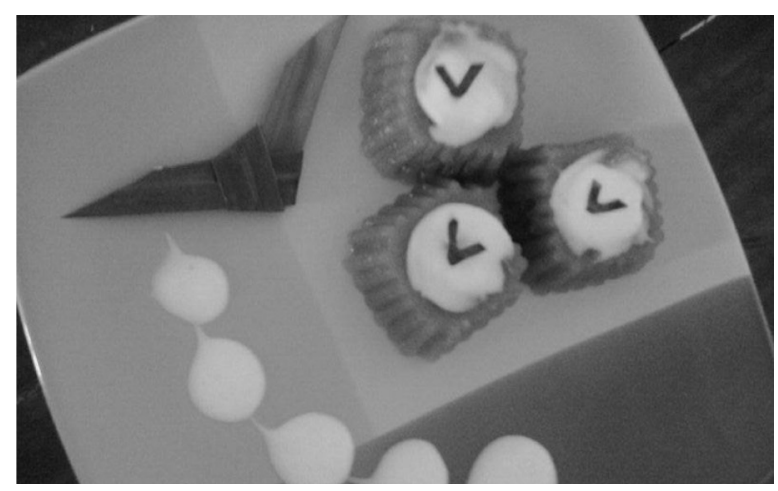

Gambar 2.Pudding Singkong Sumber: Foto Pribadi milik Tyas, 2013 
Dari gambar di atas, makanan tersebut terbuat dari singkong, tetapi ketika sudah menjadi pudding, dan dilakukan guratanguratan yang dianggap estetik. Maka citra makanan tersebut menjadi berbeda dengan citra sebelumnya, baik dalam penampilan, dan secara psikologis dapat mempengaruhi rasa.

Pada penelusuran makanan yang berestetik, adapun pengertian estetik sebagai bahan pertimbangan atas makanan dalam penyajian. Biasanya, esetika merupakan hal yang disebut sebagai nilai keindahan. Sumardjo (2010:33) mengatakan sebagai berikut:

Seni yang halus, yang transenden itu tidak bernama, tidak bisa dikatakan. Logika dan estetika berbeda, logika selalu mereruksi estetika dan estetika dimiskinkan oleh logika. Sedang sumber pengalaman seni itu ada intuisi manusia, di bawah sadarnya.Seni itu irasional.

Secara eksplisit dikatakan bahwasanya estetika bukan bagian dari logika, lebih pada pikiran bawah sadar, pengalaman, danintuisi. Hal ini menjadi dilematis ketika makanan yang biasanya disediakan secara biasa saja, disajikan dengan sentuhan estetika. Artian estetika itu sendiri menurut Kant via Hobart dan Kapferer (2005:5) sebagai berikut:

Aestheticics does not merely concern art but rather lies at the heart of the critical understanding of the human profect as a whole. And its about embodied and sensory. Art or what is defined as art engages aesthetic processe but is not their necessary or ultimate expression. The aesthetic is primary. The aesthetics forms are what human beings are already centered within as human beings.

Kant dalam kajiannya menyatakan bahwa estetika lebih mengenai penubuhan dan pengalaman sensorial manusia. Sebuah hal yang dikaitkan sebagai seni, mengalami proses estetik yang penuh dengan ekspresi. Melanjutkan dari pernyataan Kant, Estetika menurut Eagleton (1990:3) sebagai berikut:

Aesthetic is thus always a contradictory, selfundoing sort of project, which in promoting the theoretical value of its object risks emptying it of exactly that specificity or ineffability which was thought to rank among it most precious features. The very language which elevates art offers perpetually to undermine it.

Pernyataan Egleton, dapat dimaksudkan bahwa estetika merupakan sesuatu yang intuitif, tetapi sudah terjadi pada habitus manusia sebagai individu. Estetika merupakan sebuah nilai keindahan dari sebuah karya dan ciptaan. Ciptaan yang menggunakan sesuatu yang disebut intuitif, tidak menggunakan logika. Semua berdasarkan kenikmatan akan seni itu sendiri, sesuatu yang lebih mengedepankan emosi, jiwa, dan perasaan dalam melihat sebuah hal.

Berkorelasi dengan estetika, telaah lebih dalam terhadap intuitif-atau sesuatu yang dikatakan indah- pada sebuah makanan, menjadikan pemahaman baru sebagai implikasi.Terbentuk nilai keter-pesona-an dari masyarakat terhadap makanan tersebut. Penerapan pada makanan yang berestetika, terdapat nilai pesona yang muncul. Sesuatu yang mengalihkan dan tidak biasa dari sebuah hal yang biasa. Pesona merupakan sesuatu hal yang membuat tersentak dan membuat takjub terhadap suatu hal. Seperti pada penelitian Gell (1999:164) pada hasil penelitiannya terhadap Kula Canoe. Hiasan dan perangkat dikatakan mempesona karena tidak pernah terlihat sebelumnya dan adanya tingkat kesulitan yang tinggi.Kesulitan merupakan nilai pesona dari sebuah hal, sehingga semakin sebuah hal tidak biasa dan mempunyai kesulitan yang tidak sembarang orang dapat lakukan, maka pesona itu semakin kuat. Adapun sifat dari Pesona itu sendiri, menurut Gell (1999:163):

The Power of art objects stems from the technical processes they objectively embody: the technology of enchantment is founded on the enchantment of technology. The enchantment of technology is the power that technical processes have of casting a spell over us so that we see the real world in an enchanted form. The enchantment which is immanent in all kinds of technical activity. 
Menurut Gell, dari sebuah teknologi akan muncul sebuah pesona. Teknologi menyimpan sebuah tingkat kesulitan tersendiri bagi masyarakat awam. Sesuatu yang tidak biasa dan jarang dilihat. Kesulian merupakan poin dari teknik yang memunculkan pesona. Seni terbuat dari sebagai sesuatu yang kecil, rumit, halus, seperti halnya pada pahatan di kapal masyarakat Trobrian yang terdapat pesona pada hiasan. Bilamana tingkat kesulitan semakin tinggi, maka hal tersebut akan semakin mempesona.

Dari pernyataan Gell di atas, secara eksplisit menegaskan bahwa makanan dengan gaya estetik mempunyai pesona yang lebih besar. Makanan-makanan tersebut dapat saja disajikan dengan gaya biasa saja, tetapi yang membedakan adalah penyajian yang tidak biasa. Penyajian yang tidak semua orang dapat lakukan. Penyajian pada sebuah jenis makanan yang di luar kebiasaan seharihari. Adanya konsep extraordinary pada penerapan di konteks waktu everyday life. Sesuatu yang luar biasa yang diaplikasikan pada kehidupan yang biasa, yang selalu berulang. Ketika sesuatu yang berulang terbiasa dengan yang biasa, sehingga nilai yang luar biasa memberikan pesona yang lebih pada penerapannya. Pada hal ini terdapat tingkat kesulitan yang tersendiri. Seperti pada gambar Singkong yang disajikan dengan sedemikian rupa. Terdapat tingkat kesulitan yang tidak semua orang dapat melakukan, sehingga terjadi pesona. Pesona dari estetik tersebut mengonstruk pikiran dalam mempertimbangkan rasa.

\section{Komodifikasi dan Komoditisasi pada Makanan}

Pengertian selanjutnya ketika makanan dengan estetika tersebut menjadi komoditas utama dari industri pangan masyarakat, dapat disimpulkan bahwa terjadi komodifikasi pada makanan itu sendiri. Pada tataran ini, makanan berestetika tidak hanya mengalami transformasi, tetapi komodifikasi nilai. Pada dasarnya, Barker (2005:517) mengemukakan bahwa komodifikasi adalah hasil asosiasi proses atas kapitalisme. Terdapat tanda, objek dan kualitas yang dijadikan sebagai sebuah komoditas. Komoditas biasanya selalu berhubungan dengan pasar dan penjualan. Dapat dilihat bahwa komodifikasi merupakan transformasi dari sebuah barang yang tujuan akhirnya adalah komoditi, pasar. Telaah lebih lanjutnya, Smith dan Evans (2004:3233) mengemukakan bahwa komodifikasi merupakan hasil produksi dari sebuah proses kerja yang fungsinya bukan lagi untuk dipergunakan, tetapi lebih pada nilai jual beli. Baik pernyataan Barker, Smith dan Evans, menegaskan bahwa terdapat konsep yang lebih besar dari pada pertukaran nilai, tetapi jual beli. Makanan berestetik sebagai bentuk dari komoditas utama jual beli.

Bila halnya Barker, Smith, dan Evans lebih menitikberatkan permasalahan pada soal pembentukan nilai tukar menjadi jual beli. Fairclough (1995:207) menyatakan bahwa komodifikasi merupakan sebuah proses aktivitas yang tidak hanya memproduksi komoditas barang yang akan dijual, tetapi pada pengorganisasian, konseptualitas dari produksi, distribusi hingga proses konsumsinya. Jadi tidak hanya fungsi dari sebuah barang, tetapi aspek lain menjadi pertimbangan dalam pembuatan barang, yaitu pada komoditas. Penerapan makanan berestetika, dan dikaitkan dengan proses pertukaran. Terjadi perubahan serta penambahan yang terjadi pada nilai makanan itu sendiri. Ketika komodifikasi pangan berangsur menjadi komoditas, yang awalnya tidak memperhatikan bentuk, tetapi lebih ke guna. Secara eksplisit dapat dilihat sudah terjadinya proses pembentukan komoditas. Akan tetapi dalam perkembangannya kini, ternyata tidak hanya pertukaran atas nilai makanan dan uang saja, terdapat konteks baru yang berbaur dan berpadu pada makanan tersebut, yaitu seni. Makanan dengan nilai seni mempunyai tambahan nilai yang lebih tinggi dan hal tersebut dijadikan komoditas pada industri pangan global kini. Tidak terpaku pada perubahan konsep komodifikasi nilai pada pangan, sudut pandang komoditas menjadi penting ketika 
makanan berestetika menjadi komoditas itu sendiri.

Komoditas itu sendiri menurut Appadurai (1986:4) sebagai berikut:

Economic exchange creates value. Value is embodies in commodities that are exchanged. Focusing on the things are exchanged, rather than simply on the forms or functions of exchange, make it possible to argue that what creates the link between exchange and value is politics, construed broadly. Commodities like persons, have social lives.

Seperti halnya yang dikatakan Appadurai bahwa komoditas sama seperti manusia, dimana mempunyai "kehidupan sosial". Pada hal ini Appadurai menekankan tentang nilai pertukaran pada komoditas, ada nilai yang terdapat pada pertukaran. Seperti halnya barter di zaman sekarang, ketika membeli sesuatu dengan harga mahal, barang itu memang mempunyai nilai yang mahal juga. Hal tersebut serupa dengan makanan yang berestetik, di mana seperti halnya Amal menyatakan tidak keberatan untuk membeli makanan dengan harga yang lebih mahal, untuk jenis makanan yang sama. Harga yang mahal seiring dengan nilai barang yang mahal, dan pada hal ini makanan berestetik tidak hanya menjual makanan itu sendiri, tetapi menjual nilai keindahan.

Appadurai juga dalam bukunya mengangkat pernyataan Marx bahwa adanya perputaran pada komoditas selalu berhubungan dengan uang. Appadurai melihat adanya hal diluar uang yang terdapat pada komoditas seperti halnya sosial arena pada sebuah hal. Appadurai mengklasifikasikan bahwa komoditas terbagi atas empat hal, yaitu komoditas berdasarkan destinasi, metamorphosis, diversion, dan ex-comodities. Komoditas berdasarkan destinasi adalah barang yang benar-benar murni akan dijual, metamorphosis adalah barang yang berarti pada sebuah tempat karena mengalami metamorfosis, diversi adalah barang yang mengalami metamorfosis dan mengalami diversi. Ex-comodities adalah barang yang dipertukarkan ke tempat lain.
Hal tersebut membuktikan bahwa komoditas terbentuk atas jenis barang.Pada hal ini makanan mengalami proses komoditas dengan sifat metamorfosis, dimana makanan tidak hanya pada nilai makanan itu, tetapi terdapat nilai keindahan. Nilai keindahan menjadi pertimbangan sebuah makanan mempunyai harga jual yang lebih tinggi. Bahkan komoditi makanan berestetika mempunyai tempat tersendiri, seperti halnya di café, resto, dan beberapa tempat makan lainnya. Menilik perkembangan industri pangan yang masif, makanan cantik, makanan berestetik menjadi tren dan mempunyai pangsa pasar tersendiri dalam tingkat konsumerisme masyarakat yang terus melonjak. Seni dan makanan mempunyai nilai tukar yang tinggi dalam tingkat konsumerisme masyarakat

\section{Wujud Eksistensi: Saya Makan maka Saya Ada}

Saya makan maka saya ada merupakan sebuah ungkapan dalam melihat konsumerisme pangan masyarakat terhadap makanan berestetik. Setiap orang berlomba-lomba untuk pergi ke sebuah café atau resto yang menyajikan makanan atau minuman yang mempunyai pesona dan estetik. Secara implisit mengatakan bahwa mereka yang mengkonsumsi makanan yang estetik mempunyai finansial yang kuat. Makanan dengan tingkat penyajian yang tinggi mengisyarakatkan bahwa makanan tersebut dijual dengan harga yang tidak murah. Lalu bagaimana ini semua dapat menjadi wujud eksistensi, peran teknologilah yang memanjakan, dan makin menguatkan "siapa saya!".

Makanan estetik menciptakan sebuah pola baru dalam pengklasifikasian kelas sosial. Mereka yang mengkonsumsi makanan estetik akan dianggap sebagai orang berkelas, sedangkan mereka yang tidak akan dianggap sebaliknya. Pola ini sudah menjadi gaya hidup oleh sebagian orang, dan tidak dapat dipungkiri mempengaruhi pola kolektif masyarakat urban. Dalam telaah selanjutnya, masyarakat tidak lagi 
dimanjakan dengan rasa, tetapi juga pada penampilan. Penampilan pada makanan menjadi nilai tersendiri dalam keberadaan diri. Lalu, bagaimana makanan dapat merepresentasikan kelas, ternyata terdapat perangkat teknologi yang mengakomodasi hal tersebut.

Media sosial (facebook, Twitter, Instagram, Path, dan lain-lain) menjadi lambang eksistensi dari para penggunanya. Belakangan ini bahkan, tema makanan indah nan estetik menjadi tren yang kuat. Hal ini dapat dibuktikan dengan makin menaiknya profesi Food fotografer, Food Traveler dan semacamnya. Kuliner menjadi sebuah aktivitas pralambang eksistensi dari masyarakat. Pertanyaan "Apa yang dimakan?" "Di mana memakannya?" "Kapan memakannya?" "Bagaimana cara memakannya?" menjadi sebuah wujud dari eksistensi baru yang memperlihatkan "Siapa kamu?" Makanan mempunyai implikasi yang besar pada pembentukan identitas. Bila menilik pada makanan dan identitas, pembentukan identitas terbagi ke dalam tiga bentuk, yaitu primordialisme, konstruktivisme, dan instrumentalisme. Widayanti (2009:14) menyatakan bahwa

Pendekatan primordialisme menekankan identitas sebagai sesuatu yang diperoleh secara alami (given), yang terbentuk melalui sosialisasi turun-temurun. Berbeda dengan pendekatan primordialisme, pendekatan konstruktivisme memandang identitas sebagai proses sosial yang kompleks melalui ikatan-ikatan kultrural yang dibangun di dalam masyarakat. sedangkan pendekatan intrumentalisme memandang identitas sebagai seseuatu yang dikonstuksikan untuk kepentingan elit dan demi kekuasaan.

Widayanti mengelaborasikan pembentukan identitas pada 3 (tiga) tataran cara pembentukannya. Pertama adalah primordial, yaitu primordial merupakan pembentukan identitas yang lebih menekankan pada identitas yang didapat secara alami, yaitu dengan identitas yang telah membudaya. Identitas pada primordial merupakan proses turun- menurun, sehingga Identitas primordial merupakan identitas yang sangat kuat. Kedua adalah konstruktivisme merupakan pembentukan identitas yang lebih menekankan pada identitas yang didapat dengan proses interaksi. Interaksi yang dimaksud dari proses ini adalah proses sosial kekinian yang membentuk identitas dengan kekuataan kultural-kultural yang diciptakan oleh masyarakat itu sendiri. Ketiga adalah Instrumentalisme merupakan pembentukan identitas yang terjadi karena konstruksi penguasa, adanya kepentingan yang membentuk identitas ini terjadi.

Hal ini, makanan estetik merupakan wujud verbal dari pembentukan identitas secara konstruktivisme. Makanan estetik dibentuk dengan adanya pola interaksi dengan masyarakat, adanya kekuatan kultural, dan kondisi yang tercipta; sehingga membuat makanan estetik menjadi gaya hidup dan membentuk identitas masyarakat. Telaah lebih dalam terkait identitas, terdapat pespektif dalam memandang pembentukan dari posisi subjek. Hal tersebut dikemukakan oleh Hall (1990, 223-228) sebagai berikut:

Pandangan esensialime dan anti esensialisme. Pandangan yang pertama, identitas kultural dimaknai sebagai sesuatu yang satu, budaya yang digunakan bersama, semacam 'jati diri' kolektif, bersembunyi di dalam banyak hal yang lain, lebih superficial atau artifisialitas yang dipaksakan pada 'diri'. Di mana kelompok orang dengan sebuah sejarah bersama dan keturunan yang didasarkan dalam kesamaan. Dengan pengertian seperti ini identitas kultural merefleksikan pengalaman sejarah yang sama dan berbagai kode-kode kultural yang membawa kita sebagai satu masyarakat. Pandangan yang kedua, sebuah persoalan menjadi sepadan dengan being. Jauh dari menjadi 'selesai' (fixed) mereka adalah subjek dari keberlanjutan 'bermain' (play) dari sejarah, kebudayaan, dan kekuasaan.

Pembentukan terjadi dengan melihat posisi subjek berada, pada pandangan esensialis menyatakan bahwa identitas dimiliki dan digunakan bersama. Identitasi dimiliki kolektif dan terbentuk dengan 
sendirinya, salah satu contoh adalah ras keturunan. Sedangkan pada pandangan lainnya adalah anti esensial, padangan tersebut lebih menekankan bahwa seorang atau lebih merupakan bagian dari identitas tersebut. Dari hal ini dapat dilihat bahwa terdapat perbedaan dari dua pandangan,yaitu pada esensial subjek diposisikan sebagai ahli waris, pada anti esensial, subjek diposisikan sebagai bagian dari identitas, dan pembentuk identitas. Bila menilik pemikiran ini makanan estetik merupakan bagian dari pandangan anti esensial di mana, masyarakat membentuk makanan estetik pada tataran yang tinggi. Terdapat proses persetujuan dan pembentukan secara kolektif.

Makanan estetik menjadi stimulasi dalam pembentukan identitas masyarakat. Gaya hidup merupakan pembiasaan yang terjadi terus menerus oleh masyarakat, yang notabene dapat mempengaruhi seorang individu atau kelompok terpatri atas identitas tersebut. Hal lainnya yang tidak terlupakan adalah makanan estetik memang dikonstruksi oleh individu, tetapi dalam keberlangsungannya dapat mengkonstruksi orang lainnya, hal ini dapat dilihat dari wawancara Amal yang menyatakan tidak keberatan dengan makanan apa yang dijual. Nampak bahwa gaya hidup ini memetakan individu dan mengkonstruksi nilai baru dalam kebudayaan. Dari hal ini, dapat menjadi refleski untuk pembaca, bahwasanya tentang apa yang kamu makan mempunyai kekuasaan untuk menciptakan manusia, memetakan manusia, dan menguasai manusia. Makanan dapat memproyeksi seseorang berada diklasifikasi kelas sosial yang mana. Sehubungan dengan hal ini, Civitello (2008: xiv) sebagai berikut:

Everything about how humans cook and eat has meaning: who is allowed to fish for it, farm it, mill it, or kill it; what vessels and utensils are used in the preparation; what time of day the meal is eaten; who sits where at the table (if you're eating at a table), how close to an importantperson, a certain food, the salt, a person of another gender, race, or class; what order the food is served in; who serves it; whether it is hot or cold, cooked in water or by direct fire.
Secara eksplisit, Civitello dalam telaahnya menjelaskan lebih lanjut bahwa aktivitas mengkonsumsi jenis makanan dapat membedakan gender, ras, kelas, kekayaan, dan semuanya. Makanan sangat berperan besar dalam pembentukan identitas seseorang, ketika makanan menjadi tolak ukur kesejahteraan dan selera individu. Tidak dapat dipungkiri bahwa makanan merupakan aktivitas biologis terpenting manusia, dan dalam keberlangsungannya makanan tidak hanya berdiri pada nilai makanan itu saja. Peran kontekstual disekitarnya turut membentuk nilai pada makanan itu, bahkan berkali-kali lipat lebih besar dan esensial. Mengakhiri tulisan ini, sebuah syair dari penyair bernama, F.T. Marinetti menjadi refleksi bersama bahwa betapa esensialnya makanan:

"We Think, dream and act according to what we eat and drink".

\section{SIMPULAN}

Makanan sebagai artian yang kompleks menjadi sangat menarik karena tidak hanya sebagai wujud pertukaran nilai, tetapi turut membentuk nilai baru. Makanan mengalami transformasi nilai, dari hanya pertukaran atas makanan dengan uang, menjadi pertukaran nilai atas makanan tersebut. Pada hal ini, seni menjadi perpaduan dalam pertukaran nilai dari makanan. Makanan yang awalnya dipertimbangkan dengan dominasi rasa, menjadi bertambah dengan adanya pertimbangan penyajian dan penampilan dari makanan tersebut. Hal ini berimplikasi pada persoalan konsumerisme masyarakat global, yang mengkonsumsi tanpa adanya filter dan lebih mementingkan eksistensi diri.

Makanan dengan penyajian estetik, mempunyai nilai lebih dalam pertukaran nilai, sehingga nilai harga dari makanan tersebut menjadi semakin tinggi. Makanan yang estetik mempunyai pesona yang lebih, makin terlihat sulit disajikan atau jarang dilihat, maka makin mempesona, makin tinggi pada nilai harga dari makanan, dan semakin dikonsumsi. Landasan pertukaran konsep inilah yang menjadi terapan dalam proses komodifikasi 
nilai. Seni menjadi aspek yang kuat dalam menjual harga pada nilai "makanan". Makanan estetik ini menjadi komoditas utama seiring dengan terciptanya kontur kapital yang mendukung konsumerisme untuk terus berlangsung.Komodifikasi nilai pada makanan yang berbaur dengan seni menjadi wujud eksistensi masyarakat.

Keberhasilan pada komodifikasi yang terjadi membentuk komoditisasi pangan semakin legitimit. Komoditisasi pangan yang semakin masif dan dikonsumsi khalayak membuktikan bahwa terjadi antusias yang tinggi. Antusias ini menunjukan eksistensi dari si konsumen, eksistensi yang didapat tidak hanya nilai makanan, tetapi nilai kontekstual yang terdapat pada makanan. Mengingat makanan menentukan etnis, identitas, finansial kelas, gender, agama, dan kekuasaan.Makanan tidak terbentuk karena nilai makanan itu sendiri, tetapi kontekstual pada makanan turut membentuk nilai makanan menjadi lebih essensial tidak hanya pada kebutuhan, tetapi pada kehidupan.

\section{Ucapan Terimakasih kepada Narasumber:}

Amal. Laki-laki. 24 Tahun. Pekerja. Yogyakarta

Monika. Perempuan. 19 Tahun. Pelajar. Yogyakarta

\section{DAFTAR PUSTAKA}

Appadurai, Arjun. 1986. The Social Life of Things: Commodities in Cultural Perspective. Cambridge: Cambridge University Press.

'Gastro-Politics in Hindu South Asia', American Ethnologist, 8 (3),1981, 494-511.

Barker, Chris. (2005). Cultural Studies Teori dan Praktek (terj.). Yogyakarta: Bentang.

Civitello, Linda. 2008. Cuisine and Culture. New Jersey: John Wiley \& Sons, Inc

David, Smith, and Phil Evans. 1982. Marx's Kapital For Beginners. New York: Patheon.
Eagleton, Terry. 1990. The Ideology of The Aesthetic. Cambridge: Basil Blackwell

Fairclough, Norman.1995. Critical Discourse Analysis: The Critical Study of Language. Longman.

Gell, Alfred. 1999. The Art of Anthropology Essays and Diagrams. London: The Athlone Press.

Geertz, Clifford. 'Art as a Cultural System'. MLN, Vol. 91, No. 6, Comparative Literature (Dec., 1976), 1473-1499.

Kapferer, Bruce dan Angela Hobart. 2005. Aesthetic In Performance. New York: Berghagn Books.

Klindienst, Patricia. 2006. The Earth Knows My Name. Boston: Beacon Press.

Koentjaraningrat. 1994. Kebudayaan Jawa. Jakarta: Balai Pustaka.

Mintz, Sidney W. 2008. Food, Culture and Energy dalam Frank Treanmant dan Alexander Nutzenadel (ed.) Food Globalization. New York: Berg.

Parasecoli, Fabio. 2008. Bite Me Food in Popular Culture. New York: Berg.

Pelzer, K. 1963. The Agricultural Foundation. Dalam Indonesie, R.T.McVey (ed.) New Haven: HRAF Press.

Salobir, Cecilia Leong. 2011. Food Culture in Colonial Asia. London: Routledge.

Sumardjo, Jakob. 2010. Estetika Paradoks. Bandung: Sunan Ambu Press.

Spreadley, James P. 2007. Metode Etnografi. Terj Misbah Zulfa Elizabeth, Yogyakarta: PT. Tiara Wacana.

Soedarso. 2006. Trilogi Seni. Yogyakarta: Badan Penerbit Institut Seni Indonesia Yogyakarta.

This, Herve and Pierre Gagnaire. 2008. Cooking The Quintessential Art. California: University of California Press. 